\title{
Statistical Analysis of the Membership Management Indicators of the Church of England UK Dioceses during the Recent (XXth Century) "Decade of Evangelism"
}

\author{
Marcel Ausloos 1,2,*(D) and Claudiu Herteliu 2,3 \\ 1 School of Business, University of Leicester, Leicester LE2 1RQ, UK \\ 2 Department of Statistics and Econometrics, Bucharest University of Economic Studies, \\ 010374 Bucharest, Romania; hertz@csie.ase.ro \\ 3 School of Business, London South Bank University, London SE1 0AA, UK \\ * Correspondence: ma683@le.ac.uk
}

Citation: Ausloos, M.; Herteliu, C Statistical Analysis of the Membership Management Indicators of the Church of England UK Dioceses during the Recent (XXth Century) "Decade of Evangelism". Stats 2021, 4, 1069-1079. https:// doi.org/10.3390/stats4040061

Academic Editor: Wei Zhu

Received: 6 October 2021

Accepted: 11 December 2021

Published: 18 December 2021

Publisher's Note: MDPI stays neutral with regard to jurisdictional claims in published maps and institutional affiliations.

\begin{abstract}
The paper focusses on the growth or/and decline in the number of devotees in UK Dioceses of the Church of England during the "Decade of Evangelism" [1990-2000]. In this study, rank-size relationships and subsequent correlations are searched for through various performance indicators of evangelism management. A strong structural regularity is found. Moreover, it is shown that such key indicators appear to fall into two different classes. This unexpected feature seems to indicate some basic universality regimes, in particular to distinguish behaviour measures. Rank correlations between indicators measures further emphasise some difference in evangelism management between Evangelical and Catholic Anglican tradition dioceses (or rather bishops) during that time interval.
\end{abstract}

Keywords: evangelism; church of England; rank-size relationship; Lavalette function; intrinsic complexity

\section{Introduction}

On one hand, the dynamics of religious affiliation and proselytism ( For completeness, consider the definition of "proselytism". See, for example, the discussion by Fletcher in his "Preaching to convert" book [1]. One should differentiate between "proselytism", "proselytization", and also about "evangelism"; see also Fletcher text on "Proselytism" [2]. According to Schrimpf [3] in "The Goal of Evangelism: an Opportunity to Share the Gospel", "evangelism has taken on many definitions throughout the ages, [...] and much has been said about its origin in meaning. Proselytizing is not as well-known a term, but oddly enough, it has a plethora of definitions. Proselytizing, whether believer or unbeliever, has a bad connotation in society today; [...] (we) keep evangelism and proselytizing separate." In other words, Fletcher [1] explains, "To proselytize is unavoidably to express negative judgment of another's identity". Nevertheless, "proselytization" "lends itself to a less negative reading than" prozelytism "(often interpreted as unethical, coercive, or fraudulent)" [4]. Whence, one should emphasize here that evangelism, specific to the message of Jesus, in contrast to proselytism being a too general, universal, term encompassing evangelism; the latter output is the main keyword and research direction here; in fact, no determinant of any proselytism process dynamics is here studied.) are still problems of constant interest [5]. Such a process is a phenomenon similar to those processes describing crystal growths [6,7] for example. Moreover, to optimise the recruitment and conservation (fidelization) of devotees is of fundamental interest to church leaders-as it is for shop owners and customers, or also politicians [8]. This bears upon monetary problems or/and human resources [9-16], like marketing goods [15-17].

On the other hand, church leaders should understand strategies in order to maintain church vitality; one way could be through the analysis of indicators having measured 
previous methods and attempts of fidelization or/and proselytism of church goers. This would allow to pursue better strategies and forecast results after applying some logics [18]. Practically, there are many such indicators $[12,13,19]$.

Various aspects, in particular those about ritual attendance evolution, can be discussed through data extracted from the specific Church of England reports after the launching of their so-called "Decade of Evangelism" in the 1990s, following the Lambeth 1988 conference [20], specifically covering the [1990-2000] time interval; such statistical data are routinely made available by the Church of England in Church Statistics: Parochial Membership, Attendance, and Finance Statistics January to December 2000 publications [21-25]. Notice that the Evangelistic drive was a decision by the Anglican bishops for the whole world and not only for UK. In fact, the drive included not only the Anglican Church, but also the Roman Catholic Church, and most of Christian denominations. Due to data limitations, we only examine the UK dioceses here below. References to studies on intended outcomes of the 1988 Lambeth conference can be found in work by Norman [26] or by Warren [27].

Warren [27] sorted out 13 "approaches" toward evangelism ( In 1993, Robert Warren succeeded John Finney as the Church of England's National Officer for Evangelism. In 1998, he joined Springboard, the "Initiative for Evangelism" of the Archbishop of Canterbury and of York-in our words, a late initiative (, - alas?)). There were 43 (at that time) dioceses in UK. The "Diocesan performance" for 1999/2000 has been so "measured" and compared to the 1990/1991 corresponding values, "thus", covering the so-called "Decade of Evangelism".

The relative performances are practically estimated through ranking percentages of changes which have taken place when regarding 8 indicators: (i) usual Sunday attendance (uSa) number, (ii) Easter Day communicant (EDc) number, (iii) Christmas Eve/Day communicant (Xmsc) number, (iv) electoral roll membership (ERm), (v) baptism candidate number of infants (InfBp), (vi) until the 12th age (Bp12), or (vii) older (oBp), and (viii) confirmation candidate $(\mathrm{Cc})$ number.

However, the present report interest is to show that some different points of view, when analysed, going beyond a simple look at percentages, bring some interesting features. Obviously, correlations are better than simple percentage ranking [28-30]. We aim at showing correlations between growth or (more often) decay values in a rather unusual type of marketing process-congregation fidelization, whence extending the indicators as (evangelism) management criteria. We could use copulas, but they do not resolve the problem of large error bars and hidden subjectivity ( we admit such a limitation in the present context) in surveys [31]: while the method extracts information about the interdependence of variables, one must still choose a method for comparing the correlations. Thus, in this paper, we study correlations between an ordering of interdependent objective measures. Managers and economists' interest in interdependence often stems from the presence of complementarities in the problems they analyze. Therefore, our methodology is expected to suggest much more precisely meaningful work in various domains.

\section{Some Theoretical Consideration}

Our new analysis perspective is briefly discussed. It is known that one often raises some criticism on such a type of survey and subsequent studies: one can often claim that survey raw values are to be taken with caution, usually due to large error bars and hidden subjectivity.

Contrarily, rankings are thought to be illuminating and appealing, more so when there is a sort of competition. As lay arguments, taking an example in another field, consider a hiring process in academia or grant funding to research groups: the hiring is strictly based on some ranking (and committee member consensus, of course, or through a democratic-like vote procedure); the funding is usually not based on the quantitative or qualitative values of groups (how should they be measured?), relative to each other, but depends mainly on some ranking, based on conventional measures - the amount of money being finite and the research group demands being quantified. 
Let us recall another case to sustain our argument. An example of the difficulty in reaching a conclusion from mere ranking seems more illuminating than discursive sentences: consider the Premier League (soccer or football) results, each after 38 (a double round robin) plays in the last few years. Chelsea finished (second) with 71 points at the end of the 2010-2011 season, with more points that the 3rd top team in the 2011-2012 season, i.e., Arsenal, 70 points, but Chelsea was not qualified for the Champion's League, finishing sixth with 64 points. Conversely, Chelsea with 64 points, but sixth in 2011-2012 and Everton with 63 points, but sixth in 2012-2013, were not qualified for the Champion's League in the next season, even though both had more points than Tottenham, 62 points, but ended up fifth in 2010-2011. However, Tottenham had 69 points, but was sixth at the end of the 2013-2014 seasons, but did not qualified for the following Champion's League.

In brief, the gaps in points are rather masked by the ranking order. This dilemma often exists when ranking appears more important than value. We pursue the same line of thought for the dioceses and suggest discussing correlations between ranks, as distinctive sets of criteria, since the exact values of what is measured is not so precisely reliable.

Interestingly, it will be found for the UK dioceses that each indicator rank-size relationship obeys the same analytic law, with about the same precision. The strong structural regularity is next discussed; it is shown that such key indicators appear to fall into two different classes. This unexpected feature seems to indicate some basic way to distinguish performance indicator interest for managing proselytism and/or fidelization tactics.

Thus, it seems that the various attendance indicators may be advantageously examined from this so called rank-size relationship point of view. One can also observe whether the performance of dioceses was tied to bishop leadership shaped by the Evangelical or the Catholic tradition.

Possible conclusions about past and future strategies can thereby be suggested.

\section{Empirical Ranking Laws}

Let it be first recalled that nonlinearity and complexity are common features of a large number of systems studied in modern science [6,32-35]. In particular, ranking of features has received much attention. Indeed, stochastic orderings have a long history, with perhaps the most famous being those associated with the Gini coefficient. In many cases, researchers have detected the existence of power laws, for different characteristic quantities of such complex systems attributing the regularities, e.g., to self-organizations [33] or to external constraints [36], even though it is not always easy to distinguish power laws from exponential laws [37].

Specifically, within our aim and research framework, Zipf [38] observed in text studies that a large number of size distributions, $N_{r}$ can be approximated by a simple scaling (power) law $N_{r}=N_{1} / r$, where $r$ is the ranking parameter, with $N_{r} \geq N_{r+1}$, (and obviously $r<r+1)$. Zipf's idea has led to a flurry of log-log diagrams showing a straight line through the displayed data such that any size distribution, more generally called $y_{r}$, reads

$$
y_{r}=\frac{A}{r^{\alpha}}
$$

i.e., the so called rank-size scaling law. The amplitude $A$ can be estimated from the normalization condition. Therefore, for a discrete distribution, Equation (1), $A \simeq r_{M} / 2$, where $r_{M}$ is the largest rank value.

Beside the classical 2-parameter power law, Equation (1), other analytic functions can be used to model the indicator distributions. Most of the time those are not taking into account that (i) the data rank has a maximum value $r_{M}(\equiv N)$ and (ii) the value (size) distribution has often a sigmoid shape, but which is the other (descending) branch of the swastika (also known as the gammadion cross). The most simple (3 parameter) function to be used seems to be [39-43] 


$$
y_{N}(r)=\kappa_{3} \frac{(N r)^{-\gamma}}{(N-r+1)^{-\xi}} \equiv \kappa r^{-\gamma}(N-r+1)^{\xi}
$$

Note that, in Equation (2), the role of $r$ as the independent variable, in contrast to Equation (1), is taken by the ratio $r /(N-r+1)$ between the descending and the ascending ranking numbers. Observe that the slope on a log-log plot in the central region, at $r=r_{M} / 2$, is equal to $-2(\gamma+\xi)$, which should be $\simeq \alpha$.

\section{Performance Data}

The main statistical characteristics (rounded to 4 significant digits) of the value distribution for each of the 8 indicators measuring the "management performance" of the 43 UK Dioceses at the end of the "Decade of Evangelism" (1990-2000) are given in Table 1. One should at once observe that many indicators fall below the 100 p.c. level, characterizing some stationarity. However, the Bp12 and oBP point to some success, in contrast to InfBp and $\mathrm{Cc}$, which are found to be very low. At first, surprisingly, the coefficient of variation is found to be quite large for oBp and Cc. Coupled to the large skewness of the latter, this suggests some heterogeneity in the sample.

Table 1. Main statistical characteristics (rounded to 4 significant digits) of the value distribution of 8 indicators measuring "management performance" of the 43 UK Dioceses at the end of the "Decade of Evangelism" (1990-2000); the data is given in 100\% relative to 1990/91 (=100).

\begin{tabular}{ccccccccc}
\hline Indicators & $\mathbf{u S a}$ & $\mathbf{E D c}$ & $\mathbf{X m s c}$ & $\mathbf{E R m}$ & $\mathbf{I n f B p}$ & $\mathbf{B p 1 2}$ & $\mathbf{o B p}$ & $\mathbf{C c}$ \\
\hline Min. & 73 & 73 & 70 & 78 & 57 & 97 & 75 & 45 \\
Max. & 107 & 107 & 98 & 132 & 93 & 167 & 170 & 106 \\
Sum & 3655 & 3695 & 3512 & 4079 & 2896 & 5036 & 4577 & 2713 \\
Mean & 85 & 85.93 & 81.67 & 94.86 & 67.35 & 117.1 & 106.4 & 63.09 \\
Median & 84 & 85 & 82 & 94 & 67 & 118 & 103 & 62 \\
RMS & 85.23 & 86.12 & 81.81 & 95.25 & 67.68 & 117.9 & 108.7 & 63.98 \\
Std Dev. & 6.355 & 5.804 & 4.780 & 8.768 & 6.722 & 13.77 & 22.42 & 10.73 \\
Variance & 40.38 & 33.69 & 22.84 & 76.88 & 45.18 & 189.5 & 502.8 & 115.1 \\
Coeff. Var. & 1.1401 & 1.030 & 0.8925 & 1.409 & 1.522 & 1.792 & 3.213 & 2.593 \\
Std. Err. & 0.9691 & 0.8851 & 0.7289 & 1.337 & 1.025 & 2.099 & 3.419 & 1.636 \\
Skewness & 0.9007 & 0.9093 & 0.3470 & 1.650 & 1.208 & 0.9808 & 0.9545 & 1.757 \\
Kurtosis & 2.324 & 2.5990 & 2.307 & 5.791 & 3.271 & 2.1430 & 0.5570 & 4.826 \\
\hline
\end{tabular}

For information, let us report only the top 12 dioceses in our Table 2, in each indicator case; the data are \% changes for 1999/2000, relative to 1990/91 (=100).

A large variety of performances is observed according to the indicator chosen as the relevant criterion of performance. See, for example, London being out of the top 12 dioceses for InfBp, Bp12, and oBp, but being the leader in all other (5) cases. For the present purpose, three so called Evangelical dioceses, i.e., Derby, Liverpool, and Southwell are underlined, while four dioceses identified as having been, throughout the decade, under the leadership of bishops trained in Catholic theological colleges, i.e., Blackburn, Chichester, Leicester, and Truro, are bold face emphasized.

Moreover, in Table 3, we provide specific data for these 7 special dioceses for further discussion below. It is fair to observe that all these 7 dioceses performed rather similarly: all indicator measures decayed from all points of view, except for the Bp12 measure. Some discrepancy is found for the oBp indicator. In this case, Blackburn and Chichester failed in their goal, in contrast to Leicester and Truro, while Derby, Liverpool, and Southwell performed well. 
Table 2. Dioceses ranking: top 12 only, for each key indicator; the data are \% changes for 1999/2000, relative to $1990 / 91(=100)$.

\begin{tabular}{ccccccccc}
\hline $\boldsymbol{r}$ & & uSa & & EDc & & Xmsc & & ERm \\
\hline 1 & 107 & London & 107 & London & 98 & London & 132 & London \\
2 & 98 & Coventry & 95 & Southwark & 89 & Hereford & 109 & Worcester \\
3 & 97 & Canterbury & 94 & Ely & 86 & Ely & 105 & Oxford \\
4 & 93 & Derby & 93 & Guildford & 86 & Salisbury & 105 & Canterbury \\
5 & 91 & Southwark & 92 & Wakefield & 86 & Oxford & 103 & Chester \\
6 & 91 & Worcester & 92 & Sheffield & 86 & St. Eds. \& Ips. & 103 & Southwark \\
7 & 90 & Oxford & 91 & Gloucester & 86 & Sod. \& Man & 101 & Hereford \\
8 & 89 & Sod. \& Man & 91 & Worcester & 86 & Gloucester & 101 & Portsmouth \\
9 & 88 & Ely & 90 & Salisbury & 85 & Norwich & 101 & Chelmsford \\
10 & 88 & St. Eds. \& Ips. & 90 & Oxford & 85 & Truro & 100 & Wakefield \\
11 & 88 & Peterborough & 90 & St. Eds. \& Ips. & 85 & Winchester & 99 & Manchester \\
12 & 87 & Hereford & 89 & Hereford & 84 & Bradford & 99 & St. Eds. \& Ips. \\
\hline $\boldsymbol{r}$ & \multicolumn{1}{c}{ InfBp } & & Bp12 & & oBp & & Cc \\
\hline 1 & 93 & Sod. \& Man & 167 & Sod. \& Man & 170 & Sheffield & 106 & London \\
2 & 80 & Carlisle & 139 & York & 155 & Ely & 88 & Sod. \& Man \\
3 & 75 & Worcester & 137 & Worcester & 153 & Lincoln & 84 & Blackburn \\
4 & 75 & Southwell & 133 & Blackburn & 150 & Worcester & 75 & Birmingham \\
5 & 74 & Salisbury & 131 & Lincoln & 135 & Derby & 74 & Southwark \\
6 & 74 & Lincoln & 130 & Carlisle & 133 & Sod. \& Man & 71 & Liverpool \\
7 & 73 & Wakefield & 128 & Leicester & 130 & Salisbury & 70 & Chelmsford \\
8 & 73 & Chelmsford & 127 & Southwell & 130 & Portsmouth & 68 & Wakefield \\
9 & 73 & Coventry & 126 & Durham & 120 & Coventry & 67 & Leicester \\
10 & 71 & St. Eds. \& Ips. & 125 & Lichfield & 120 & Truro & 67 & Guildford \\
11 & 71 & Ely & 125 & Sheffield & 115 & Lichfield & 67 & St Albans \\
12 & 70 & Guildford & 125 & Wakefield & 113 & Southwell & 66 & Winchester \\
\hline
\end{tabular}

Table 3. The, in alphabetical order, so-called (3, underlined and in italics) Evangelical and (4, bold faced) Catholic tradition dioceses for each 8 key indicators; the data are \% changes for 1999/2000, relative to $1990 / 91(=100)$.

\begin{tabular}{ccccccccc}
\hline & uSa & EDc & Xmsc & ERm & InfBp & Bp12 & oBp & Cc \\
\hline Blackburn & 82 & 80 & 80 & 82 & 62 & 133 & 80 & 84 \\
Chichester & 86 & 89 & 83 & 96 & 67 & 103 & 93 & 57 \\
Derby & 93 & 89 & 81 & 91 & 58 & 121 & 135 & 54 \\
Leicester & 87 & 85 & 81 & 87 & 69 & 128 & 103 & 67 \\
Liverpool & 81 & 79 & 78 & 89 & 62 & 118 & 105 & 71 \\
Southwell & 79 & 84 & 75 & 90 & 75 & 127 & 113 & 58 \\
Truro & 84 & 83 & 85 & 83 & 65 & 115 & 120 & 56 \\
\hline
\end{tabular}

\subsection{Percentage Change Data Analysis}

The data analysis is reported in Figure 1: a different color and symbol are used for distinguishing the indicators, as mentioned in the inset to make the data as readable as possible. The change in curvature (near $r=20$ ) points to two types of regimes and reinforces the present consideration of re-examining the performance evaluation in a different perspective than as done by Francis and Roberts [25]. For completeness, the error characteristics from the fit regressions, i.e., $\chi^{2}$, and the $R^{2}$ regression coefficient, are given in Table 4 . Each $\chi^{2}$ value is rounded to the closest integer. 
Table 4. Parameter values and respective error bars for the 3-parameter free fit (through a LevenbergMarquardt algorithm) with Equation (2) to the rank-size relationships of the 8 indicators, corresponding to Figure 1.

\begin{tabular}{ccccccc}
\hline & $\kappa$ & $\gamma$ & $\xi$ & $\chi^{\mathbf{2}}$ & $\boldsymbol{R}^{\mathbf{2}}$ & $\mathbf{- 2}(\boldsymbol{\gamma}+\boldsymbol{\xi})$ \\
\hline uSa & $91.60 \pm 1.93$ & $0.057 \pm 0.004$ & $0.030 \pm 0.004$ & 69 & 0.959 & -0.17 \\
EDc & $91.24 \pm 1.81$ & $0.051 \pm 0.004$ & $0.029 \pm 0.004$ & 63 & 0.956 & -0.16 \\
Xmsc & $80.60 \pm 1.74$ & $0.033 \pm 0.004$ & $0.037 \pm 0.004$ & 65 & 0.932 & -0.14 \\
ERm & $108.45 \pm 3.86$ & $0.076 \pm 0.006$ & $0.028 \pm 0.007$ & 251 & 0.922 & -0.21 \\
InfBp & $75.51 \pm 2.30$ & $0.078 \pm 0.005$ & $0.036 \pm 0.006$ & 91 & 0.952 & -0.23 \\
Bp12 & $129.60 \pm 4.99$ & $0.087 \pm 0.007$ & $0.049 \pm 0.008$ & 437 & 0.945 & -0.27 \\
oBp & $127.21 \pm 4.65$ & $0.155 \pm 0.006$ & $0.085 \pm 0.008$ & 317 & 0.985 & -0.48 \\
Cc & $86.46 \pm 4.31$ & $0.150 \pm 0.008$ & $0.034 \pm 0.011$ & 226 & 0.953 & -0.37 \\
\hline
\end{tabular}

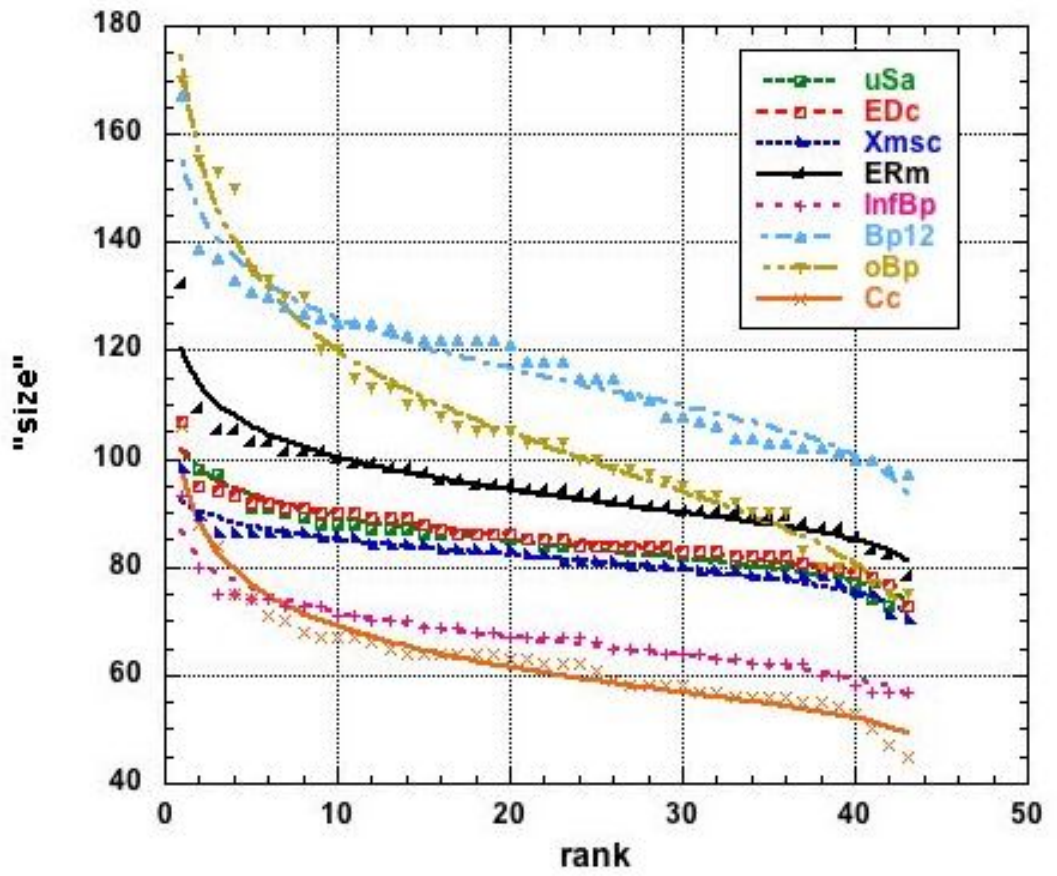

Figure 1. Plot of the rank-size distribution of the 43 diocese for 8 key indicators measuring evangelism performance; the lines are fits done with the 3-parameter function Equation (2); $\chi^{2}$ and $R^{2}$ values are given in Table 4.

\subsection{Result Discussion}

According to Figure 1, it appears that a remarkably similar structure occurs for each indicator rank relationship, even though the dioceses are much exchanging their ranks, based on their respective growth or decay values, as seen in Table 2. Moreover, the slopes at mid $r_{M}$ seemed to be grouped into two classes. A very large slope (in absolute value) indicates a large variation in performance between the dioceses for the relevant indicator. Notice that from the raw data published by Francis and Roberts [25], there is no cue indicating that the baptism candidate numbers of older $(\mathrm{oBp})$ religious adherents and the confirmation candidate (Cc) numbers would be specifically correlated. Observe that the correlation reduces the surprise about the coefficient of variation found to be quite large for $\mathrm{oBp}$ and $\mathrm{Cc}$, in Table 1. Recall that this suggests some heterogeneity in the sample. However, this seems a coherent effect, since adherence to the church by older persons, through baptism, are quasi-necessarily going to be followed by the sacrament of confirmation.

Therefore, we emphasize a posteriori that such criteria indicate a particular endeavour (or positive performance) toward some conversion of the old population, in the various dioceses during the Evangelism decade. 
This occurrence of different class criteria is confirmed by observing Figure 2, in which the two criteria about the old population conversion are markedly distinguished from the others.

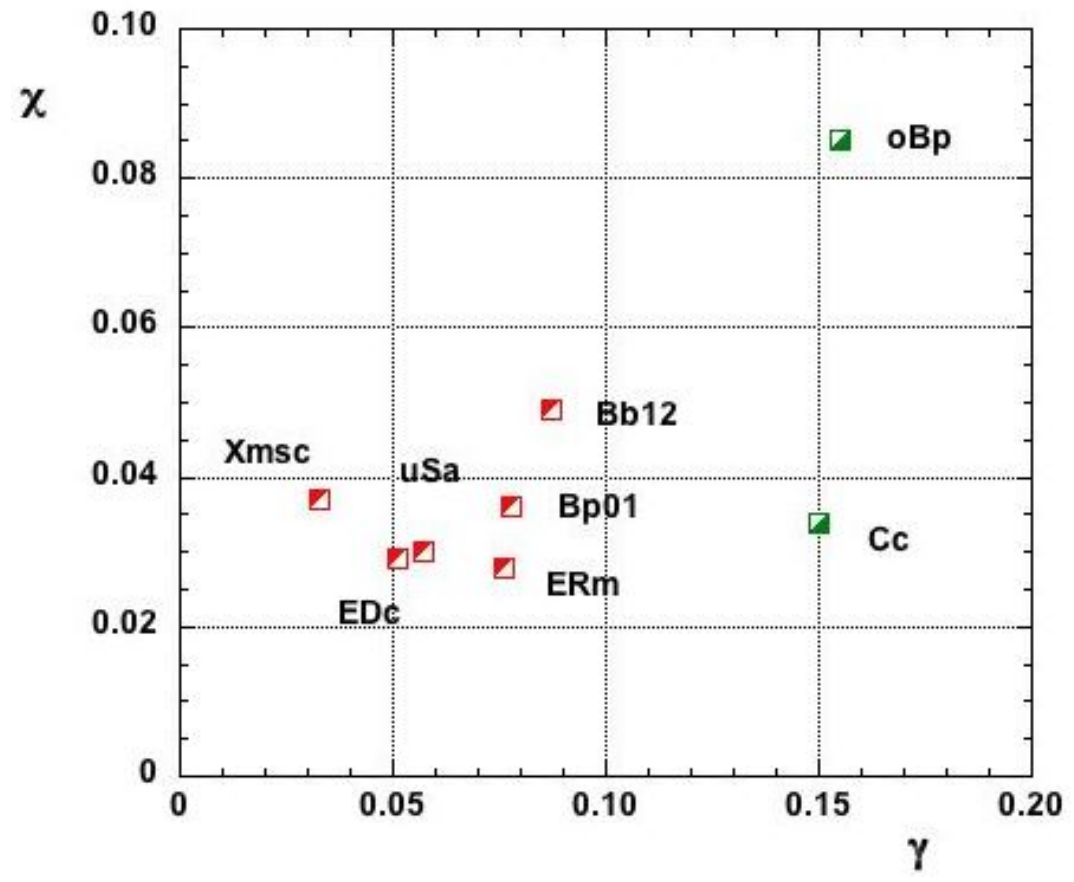

Figure 2. Distribution of $\gamma$ and $\xi$ exponent values given in Table 4 for the 8 mentioned evangelism performance indicators.

\section{Rank Correlation Data}

As mentioned in the introduction and the theoretical discussion on the methodology, the comparison only through percentage values is debatable when the measures are not well standardized. For comparing the dioceses, a rank correlation analysis is more appropriate. This is best made through the so-called Kendall $\tau$ measure [44]. Introduced by Kendall in 1938 [45], it compares the number of concordant pairs $p$ and non-concordant pairs $q$ in an equal size list through

$$
\tau=\frac{p-q}{p+q}
$$

Of course, $p+q=N(N-1) / 2$, where $N$ is the number of measures, when there is no rank overlap.

From a purely statistical perspective, under the null hypothesis of independence of the rank sets, such a sampling would have an expected value $\tau=0$. A positive (negative) $\tau$ indicates a high (low) rank correlation. A Wessa website [46] allows $\tau^{\prime}$ s immediate calculation.

\subsection{Rank Correlation Data Analysis}

In the case of the $43 \mathrm{UK}$ dioceses, some percentage measure has surely been rounded to only two decimals by FR. This leads to apparently equal percentage values. For examples, Ely, St. Eds. \& Ips. ( abbreviation for St. Edmundsbury and Ipswich), and Peterborough dioceses cannot be distinguished from the uSa point of view, nor Ely, Salisbury, Oxford, St. Eds. \& Ips., Sod. \& Man, and Gloucester from the Xmsc point of view.

\subsection{Result Discussion}

The data reported in Table 5 indicates that there is a high rank correlation (a large $\tau$ value) between uSa, EDc, Xmasc, and ERm-the more so between Easter and Christmas service attendance, as could have been expected. Notice a contrario the largest negative values $\tau=-0.0934$ and $\tau=-0.0789$ : they occur for the rank correlations between ERm 
and $\mathrm{Bp} 12$, on one hand and for the oBp and Cc. Since the rank correlation between ERm and $C_{c}$ is rather large $(\tau=-0.249)$, the findings might be attributed to different age pyramids in the dioceses or were locally adapted to some type of population. Our conclusion might be that different strategies in each diocese should have been implemented for a better performance, and should thereafter be considered at a more microscopic level in order to optimize the outcome.

Table 5. Kendall $\tau$ rank correlation coefficient for comparing 7 pairs of ranks for the 43 UK dioceses according to the column and row indicators.

\begin{tabular}{cccccccc}
\hline Kendall $\boldsymbol{\tau}$ & EDc & Xmsc & ERm & InfBp & Bp12 & oBp & Cc \\
\hline uSa & 0.430 & 0.271 & 0.296 & 0.129 & -0.00575 & 0.182 & 0.216 \\
EDc & & 0.553 & 0.303 & 0.267 & -0.0471 & 0.198 & 0.164 \\
Xmsc & & & 0.180 & 0.201 & -0.113 & 0.0383 & 0.183 \\
ERm & & & & 0.0426 & -0.0934 & 0.0478 & 0.249 \\
InfBp & & & & & 0.352 & 0.198 & 0.0717 \\
Bp12 & & & & & & 0.178 & 0.0756 \\
oBp & & & & & & & -0.0789 \\
\hline
\end{tabular}

Moreover, examining the 7 specific dioceses, notice from Table 3 that rank overlap occurs only for the EDc and Xmsc indicators. The $\tau$ coefficient values are given in Table 6. Thus, it is interesting to notice that the largest anti-correlation exists for the pairs oBp and $C_{c}(\tau=-0.619)$, whence indicating that for these 7 dioceses the Cc ranking is NOT due to the oBp, but rather to the Bp12 performance $(\tau=0.429)$. Notice also that all $\tau$ values are negative when implying the Bp12 indicator-the most negative value occurring for the ERm/Bp12 case, as in the case of the whole UK (Table 5). The implemented strategy of such 7 dioceses, in this respect, is not a point of discussion for the present paper. Even though such a study is very interesting, it goes much beyond the aim of this paper.

Table 6. Kendall $\tau$ rank correlation coefficient for comparing pairs of ranks for the 7 specifically interesting (see list in text) dioceses according to the column and row indicators; to be contrasted with Table 5 .

\begin{tabular}{cccccccc}
\hline Kendall $\boldsymbol{\tau}$ & EDc & Xmsc & ERm & InfBp & Bp12 & oBp & Cc \\
\hline uSa & 0.586 & 0.488 & 0.143 & -0.098 & -0.143 & 0.143 & -0.333 \\
EDc & & 0.350 & 0.586 & 0.150 & -0.195 & 0.098 & -0.488 \\
Xmsc & & & 0.000 & -0.150 & -0.390 & 0.000 & -0.390 \\
ERm & & & & 0.098 & -0.429 & 0.238 & -0.429 \\
InfBp & & & & & -0.098 & -0.098 & 0.098 \\
Bp12 & & & & & & -0.238 & 0.429 \\
oBp & & & & & & & -0.619 \\
\hline
\end{tabular}

\section{Concluding Remarks}

The mathematical modeling of church growth [5,47] needs some further studies of simple properties. Here above we took the case of the analysis of the growth (or decline) in the Church of England during the Decade of Evangelism [1990-2000] in order to provide such an insight into maintaining devotees and/or acquiring them. We went further than a mere observation and discussion of the percentage values of growth and decay indicators, based on the modern ideas of investigations about complex systems: (i) the classical ranksize relationship $[38,48,49]$, underlying the description of social complex systems, has been first examined; (ii) next, avoiding a debatable comparison and discussion of the measured values, we have focused on the ranking correlations.

It appears that the rank-size distribution contains 2 classes of indicators with a quite different mid-rank exponent, about -0.15 or -0.40 , suggesting a sort of separation between criteria measurements. The (vii) older (oBp) and the (viii) confirmation candidate (Cc) numbers point toward a much greater diversity between the dioceses-which better 
emphasizes their performance. Beside, through this search for an empirical law, on the rank-size relationship of diocese performance indicators, a universal sort of function has been proposed. This unexpected feature may suggest, in particular, a method to distinguish between behavior measures when performing other studies on religious adhesion and performance. Moreover, an examination of the rank-rank correlations seems to indicate that evangelism strategies might have to be adapted to age pyramids, or more locally adapted to the type of population.

The discussed results are obviously specific to the data, i.e., the Church of England, and the decade of interest (the end of last century). There are other religions with a binary-like bishop education, e.g., in protestant, in orthodox, in moslem structures, and sometimes with more than two "branches". All religious leaders tend to maintain their flock in their own giron. It is most likely, but this is only a guess, that in order to maintain and/or to increase the number of practitioners, the marketing is rather similar to the presently studied case. The proselytism strategies should differ in the details, due to social parameters, depending on demography, geography, political structures, and other society characteristics, but the "over all" findings should remain a rather universal basis on which to implement some growth incentive strategies.

From our selection of two types of dioceses (or rather bishops), let us observe that both Catholics and Evangelicals leaders aimed the Church's top priority as being at working with young people. Interestingly, Evangelicals leaders placed personal witness ("proselytism") as a second priority with clergy visiting ("fidelization") being the third, while Catholics leaders placed clergy visiting second and personal witness third. Thus, one reconciles the anomalies, at first, in data for Derby, Liverpool, and Southwell, on one hand, and for Blackburn, Chichester, Leicester, and Truro, on the other hand. In some sense, one can consider the management aspect as a resulting behavior due to specific bishop education (taken in a broad sense): Evangelical Colleges rather stress biblical theology, biblical inspiration, and authority, leading to personal conversion (by grace through faith), the centrality being the preaching ministry role [50]. In contrast, Anglo-Catholic Colleges stress sacramental theology, sacramental grace, confession, and the centrality of sacramental ministry, richness in Eucharistic ritual and ornaments, as a more "flashy" attraction.

In so doing, the Evangelical officers showed greater commitment to Sunday school activities among children and young people. However, the Catholic priests conducted a higher proportion of infant baptisms and admitted children to confirmation at a younger age. This is a hypothesis following ("correlating") the splitting of the data into two types of measurements. Of course, it would be very interesting to study such a type of measures at the parish level, distinguishing how many worship places claimed some identity-even with ... for ... a given bishop, but that type of regression analysis is only suggested for further work.

Going much further than the present paper aim, some modeling can be imagined in future work, along the lines of open systems in a necessarily non-equilibrium and timedependent state. The results might indicate how to optimize evangelism strategies. In such a line of thought, we suggest some further work based on a more microscopic level, that of parishes and worship places.

Moreover, if the leadership of the Church of England is again interested in renewing some evangelism process, through proseltyzation or not, it seems that to increase its visibility and its attractiveness demands to take into account our findings, in particular, in order to develop strategies according to specific population targets, including nowadays, modern techniques like artificial intelligence and other new technologies [51]. This is quite similar-we repeat our assumption framework, to marketing goods. It seems interesting to pursue the matter by considering determinants of consumer behavior, like developing regression models searching for key attributes in specific societies. This study is outside our present aim, however. Whether the determinants depend on congregations, i.e., their causal linkages, is a highly challenging question-yet, as old as sect creation. 
Finally, we could mention, like a few others, see [4], that religious conversion, through prozelytization or not, and congregation fidelization are some sort of marketing process. (As pointed out by a reviewer, migration could be a variable also to be taken into account ( Migration data would be of interest but will never be likely available due to the General Data Protection Regulation; whence this comment can only remain as a hypothesis)). A newcomer in a neighbourhood will most likely choose to follow / attend the most attractive bishop/church from her/his proximity. It is a known social criterion in several countries: "to what church do you belong?". Therefore, the choice of the newcomer will be like the result of marketing for a new customer. Notice that Fletcher [1] even considers evangelism mission as being like a theater play. If we are first to point out that one could study the proselytism process dynamics through a regression analysis, and later differential equations, like it is done for discussing consumer behaviors in economy, we are proud to be the pioneers!

Author Contributions: All authors have equally contributed to the paper within their respective skills. All authors have read and agreed to the published version of the manuscript.

Funding: Marcel Ausloos and Claudiu Herteliu are partially supported by the project: "Understanding and modelling time-space patterns of psychology-related in- equalities and polarization", code PN-III-P4-ID-PCCF-2016-0084.

Institutional Review Board Statement: Not Applicable.

Informed Consent Statement: Not Applicable.

Data Availability Statement: Data is available as mentioned through the references.

Acknowledgments: A preliminary version of this manuscript was presented at the "Globalization and Higher Education in Economics and Business Administration-GEBA 2021" Conference, Alexandru Ioan Cuza University of Iasi, 21-22 October 2021

Conflicts of Interest: The authors declare no conflict of interest.

\section{References}

1. Fletcher, J. Preaching to Convert: Evangelical Outreach and Performance Activism in a Secular Age; University of Michigan Press: Ann Arbor, MI, USA, 2013.

2. Fletcher, J. Proselytism. Ecumenica 2014, 7, 67-70.

3. Schrimpf, A. The Goal of Evangelism: An Opportunity to Share the Gospel. Thesis, Wisconsin Lutheran Seminary, 2017. Available online: http:/ / essays.wisluthsem.org:8080/bitstream/handle/123456789/4314/Schrimpf.pdf? sequence=3\&isAllowed=y (accessed on 1 December 2021).

4. Hackett, R.I.J. Proselytization Revisited: Rights Talk, Free Markets and Culture Wars; Routledge: Abingdon, UK, 2014.

5. Ausloos, M.; Petroni, F. Statistical dynamics of religions and adherents. Europhys. Lett. 2007, 77, 38002. [CrossRef]

6. Gadomski, A. Kinetic Approach to the Nucleation-and-Growth Phase Transition in Complex Systems. Nonlinear Phenom. Complex Syst. 2000, 3, 321-352.

7. Gadomski, A.; Siódmiak, J.; Santamaria-Holek, I.; Rubí, J.M.; Ausloos, M. Kinetics of growth process controlled by mass-convective fluctuations and finite-size curvature effects. Acta Phys. Pol. B 2005, 36, 1537-1559.

8. Eckhardt, G.M.; Varman, R.; Dholakia, N. Ideology and critical marketing studies. In The Routledge Companion to Critical Marketing; Routledge: Abingdon, UK, 2018; pp. 306-318.

9. Stark, R.; Bainbridge, W.S. Networks of faith: Interpersonal bonds and recruitment to cults and sects. Am. J. Sociol. 1980, 85, 1376-1395. [CrossRef]

10. Cutler, B.D. Religion and marketing: Important research area or a footnote in the literature? J. Prof. Serv. Mark. 1992, 8, 153-164. [CrossRef]

11. Iannaccone, L.R.; Olson, D.V.; Stark, R. Religions resources and church growth. Soc. Forces 1995, 74, 705-731. [CrossRef]

12. Herteliu, C. Statistical Indicators System regarding Religious Phenomena. J. Study Relig. Ideol. 2007, 6, 115-131.

13. Herteliu, C.; Isaic-Maniu, A. Statistical Indicators for Religious Studies: Indicators of Level and Structure. J. Appl. Quant. Methods 2009, 4, 524-530.

14. Ausloos, M. Econophysics of a religious cult: The Antoinists in Belgium [1920-2000]. Phys. A Stat. Mech. Its Appl. 2012, 391, 3190-3197. [CrossRef]

15. Hodøl, H.-O. What a Friend We Have in Facebook: Norwegian Christian Churches' Use of Social Media. J. Media Relig. 2021, 20, 123-142. [CrossRef] 
16. Siuda-Ambroziak, R.; Stachowska, E. Religious market and its entrepreneurs: Comparative perspective on Brazil and Poland. Probl. Zarz. 2017, 15, 24-44. [CrossRef]

17. Stark, R.; Finke, R. A Theoretical Model of Religious Economies. In Acts of Faith; University of California Press: Berkeley, CA, USA, 2000; pp. 193-217.

18. Pestroiu, D. Characteristics of Adventist-Millenarian Proselytism in Romania, in the Aftermath of 1989. Teologia 2020, 82, 49-62.

19. Brewer, E.D.C. Social Indicators and Religious Indicators. Rev. Relig. Res. 1973, 14, 77-90. [CrossRef]

20. Church of England. The Truth Shall Make You Free: The Lambeth Conference 1988; The Reports, Resolutions E Pastoral Letters from the Bishops; Church House Publishing: London, UK, 1988.

21. Church of England, The Central Board of Finance. Church Statistics: Some Facts and Figures about the Church of England; The Central Board of Finance: London, UK, 1992.

22. Church of England, The Central Board of Finance. Church Statistics: Some Facts and Figures about the Church of England; The Central Board of Finance: London, UK, 1993.

23. Church of England. Church Statistics: Parochial Membership and Finance Statistics January to December 1999; Church House Publishing: London, UK, 2001.

24. Church of England, The Central Board of Finance. Church Statistics: Parochial Membership, Attendance, and Finance Statistics January to December 2000; Church House Publishing: London, UK, 2002.

25. Francis, L.J.; Roberts, C. Growth or Decline in the Church of England during the Decade of Evangelism: Did the Churchmanship of the Bishop Matter? J. Contemp. Relig. 2009, 24, 67-81. [CrossRef]

26. Norman, E.R. Anglicanism and the Lambeth Conference of 1988. Angl. Episcop. Hist. 1989, 58, 370-378.

27. Warren, R. Signs of life: How goes the Decade of Evangelism. Anvil 1995, 13, 7-19.

28. Giovagnoli, A.; Wynn, H.P. Stochastic orderings for discrete random variables. Stat. Probab. Lett. 2008, 78, 2827-2835. [CrossRef]

29. Müller, A.; Stoyan, D. Comparison Methods for Stochastic Models and Risks; Wiley: New York, NY, USA, 2002 ; Volume 389.

30. Rüschendorf, L. Solution of a statistical optimization problem by rearrangement methods. Metrika 1983, 30, 55-61. [CrossRef]

31. Cerqueti, R.; Rotundo, G.; Ausloos, M. Investigating the configurations in cross-shareholding: A joint copula-entropy approach Entropy 2018, 20, 134. [CrossRef]

32. Axelrod, R.; Cohen, M.D. Harnessing Complexity: Organizational Implications on a Scientific Frontier; Free Press: New York, NY, USA, 1999.

33. Bak, P.; Tang, C.; Wiesenfeld, K. Self-organized criticality: An explanation of 1/f noise. Phys. Rev. Lett. 1987, 59, 381-384. [CrossRef]

34. Vitanov, N.K.; Jordanov, I.P.; Dimitrova, Z.I. On nonlinear dynamics of interacting populations: Coupled kink waves in a system of two populations. Commun. Nonlinear Sci. Numer. Simul. 2009, 14, 2379-2388. [CrossRef]

35. Kwapień, J.; Drożdż, S. Physical approach to complex systems. Phys. Rep. 2012, 515, 115-226. [CrossRef]

36. Ausloos, M. New Region Planning in France? Better Order or More Disorder? Entropy 2015, 17, 5695-5710. [CrossRef]

37. Ausloos, M.; Miskiewicz, J.; Sanglier, M. The durations of recession and prosperity: Does their distribution follow a power or an exponential law? Physica A 2004, 339, 548-558. [CrossRef]

38. Zipf, G.K. Human Behavior and the Principle of Least Effort: An Introduction to Human Ecology; Addison Wesley: Cambridge, MA, USA, 1949.

39. Popescu, I. On a Zipf's Law Extension to Impact Factors. Glottometrics 2003, 6, 83-93.

40. Lavalette D. A general purpose ranking variable with applications to various rankng laws. In Exact Methods in the Study of Language and Text: Dedicated to Gabriel Altmann on the Occasion of His 75th Birthday; Grzybek, P., Köhler, R., Eds.; Walter de Gruyter: Berlin, Germany, 2011; Volume 62. pp. 371-382.

41. Ausloos, M. Two-exponent Lavalette function: A generalization for the case of adherents to a religious movement. Phys. Rev. E 2014, 89, 002800. [CrossRef]

42. Ausloos, M. Toward fits to scaling-like data, but with inflection points \& generalized Lavalette function. J. Appl. Quant. Methods 2014, 9, 1-21.

43. Ausloos, M.; Cerqueti, R. A universal rank-size law. PLoS ONE 2016, 11, e0166011. [CrossRef]

44. Nelsen, R.B. An Introduction to Copulas; Springer Science \& Business Media: Berlin/Heidelberg, Germany, 1999.

45. Kendall, M.G. Rank Correlation Methods, 4th ed.; Griffin: London, UK, 1976.

46. Wessa. Kendall tau Rank Correlation (v1.0.13) in Free Statistics Software (v1.2.1), Office for Research Development and Education. 2017. Available online: https:/ / www.wessa.net/rwasp_-kendall.wasp/ (accessed on 29 July 2019).

47. Hayward, J. Mathematical Modeling of Church Growth. J. Math. Sociol. 1999, 23, 255-292. [CrossRef]

48. Newman, M.E.J. Power laws, Pareto distributions and Zipf's law. Contemp. Phys. 2005, 46, 323-351. [CrossRef]

49. Brakman, S.; Garretsen, H.; van Marrewijk, C.; van den Berg, M. The Return of Zipf: Towards a Further Understanding of the Rank-Size Distribution. J. Reg. Sci. 1999, 39, 182-213. [CrossRef]

50. Francis, L.J.; Lankshear, D.W. The comparative strength of Evangelical and Catholic Anglican churches in England. J. Empir. Theol. 1996, 9, 5-22. [CrossRef]

51. Gavriluţă, N. The New Technologies and Camouflaged Mythologies of Transhumanism. Hermeneia 2020, 25, 54-59. 